\title{
A inserção das mulheres no mercado de trabalho como uma exigência do capital e a divisão sexual do trabalho
}

\section{Maria Fernanda Soares Fonseca}

\begin{abstract}
Advogada, inscrita na Ordem dos Advogados do Brasil sob o n 132.889 , Seção Minas Gerais. Possui graduação em Direito pela Universidade Estadual de Montes Claros (2011) e pós-graduação em Direito Constitucional Aplicado com capacitação para o Ensino no Magistério Superior, pela Faculdade de Direito Damásio de Jesus (2013). É Mestranda no Programa de Pós-Graduação em Desenvolvimento Social (PPGDS) da Universidade Estadual de Montes Claros. É professora Orientadora de TCC (Trabalho de Conclusão de Curso) na Funorte, nos cursos de Direito e Serviço Social e ministra as disciplinas Legislação em Serviço Social e Direitos Humanos no Brasil no curso de Serviço Social. Presta Consultoria Jurídica para empresas, foi Assessora Jurídica do Centro de Referência Especializado de Assistência Social (CREAS) da Secretaria de Assistência Social da Prefeitura de Capitão Enéas/MG, e o é, atualmente, da Gerência de Gestão do Sistema Único de Assistência Social (SUAS) da Prefeitura de Montes Claros/ MG, na qual compõe equipe de Supervisão Técnica das Unidades de Acolhimento Institucional da Proteção Social Especial de Alta Complexidade. Em 2015 foi nomeada Conselheira e Primeira-Secretária do Conselho Municipal de Assistência Social da cidade de Montes Claros.
\end{abstract}

\section{Resumo}

Esse artigo propõe analisar a relação do modelo de desenvolvimento capitalista implantado no Brasil, com a questão da desigualdade de gênero e seu impacto na inserção da mulher no mercado de trabalho. Embora estatísticas demonstrem a crescente inserção das mulheres no mercado de trabalho, a questão da discriminação das mulheres é histórica e atualmente pode-se vislumbrar tal quadro, que impacta diretamente nas relações sociais e consequentemente na divisão sexual do trabalho. Diante de pesquisas divulgadas é possível observar a inserção da mulher no mercado de trabalho e as diversas formas de manifestação da desigualdade de gênero, seja na questão salarial, seja nas posições que as mulheres ocupam e as relações de discriminação que são criadas. Para desenvolvimento do artigo foram utilizados os métodos de pesquisa bibliográfica e documental, ou seja, trata-se de um estudo da relação opressiva e predatória do sistema capitalista com as questões que permeiam a desigualdade de gênero.

Palavras-chave: Mulheres. Capitalismo. Divisão Sexual do Trabalho.

\section{Abstract}

This article aims to analyze the relationship of the capitalist development model implemented in Brazil, with the issue of gender inequality and its impact on women entering the labor market. Although statistics show the increasing entry of women into the labor market, the issue of discrimination against women is historically and currently can be glimpsed such a framework, which directly impacts on social relationships and therefore the sexual division of labor. Before released research it can see the women entering the labor market and the various manifestations of gender inequality, either in the salary issue, or in positions that women hold and the relationships of discrimination that are created. For the development of Article methods of bibliographic and documentary research were used, ie it is a study of the oppressive and predatory relation of the capitalist system with the issues that underlie gender inequality.

Keywords: Women. Capitalism. Sexual Division of Labor.

\section{Resumen}

Este artículo tiene como objetivo analizar la relación entre el modelo de desarrollo capitalista implantado en Brasil, con el tema de la desigualdad de género y su impacto en las mujeres que entran en el mercado laboral. Aunque las estadísticas muestran la entrada creciente de las mujeres en el mercado laboral, la cuestión de la discriminación contra la mujer está históricamente y en la actualidad se puede vislumbrar ese marco, lo que impacta directamente en las relaciones sociales y, por tanto, la división sexual del trabajo. Antes lanzado la investigación se puede ver a las mujeres que entran en el mercado laboral y las diversas manifestaciones de la desigualdad de género, ya sea en la edición de salario, o en posiciones que las mujeres poseen y las relaciones de discriminación que se crean. Para el desarrollo del Artículo métodos de investigación bibliográfica y documental fueron utilizados, es decir, se trata de un estudio de la relación opresiva y depredadora del sistema capitalista con las cuestiones que subyacen a la desigualdad de género 
Palabras clave: Mujeres. Capitalismo. Trabajo División sexual.

\section{Introdução}

As questões que permeiam o universo feminino perpassam pelas mais variadas nuances do desenvolvimento e do conhecimento, quer seja para compreender a evolução dos direitos das mulheres no decorrer dos séculos, quer seja observar na percepção de que, apesar da supracitada evolução, alguns estigmas e paradoxos permanecem inalterados.

Todo mundo sabe que a mulher sempre foi discriminada, nunca teve as mesmas oportunidades asseguradas aos homens. Nossa cultura patriarcal gerou uma sociedade machista, em que a mulher ocupava um papel subalterno. Excluída, ficava confinada ao reduto da casa, tendo por única missão a assistência da família, a organização do lar, o apoio ao marido e o cuidado dos filhos. (DIAS, 2004, p. 20)

Necessário se faz, portanto, antes de adentrar na temática da divisão sexual do trabalho, compreender as noções e construções do conceito de gênero para, posteriormente, discutir a inserção da mulher no mercado de trabalho como uma exigência do capital.

No caso brasileiro, o modelo de desenvolvimento capitalista implantado em seus primórdios e que até hoje permanece, mais gera e cria desigualdades, do que efetivamente desenvolvimento, a despeito de estar disfarçado pelo paradigma nacional-desenvolvimentista da geração de emprego e renda. Em outras palavras, não é possível dissociar a questão da desigualdade de gênero nas relações sociais das relações de trabalho, da opressão e da característica predatória das relações capitalistas.

Apesar de reconhecer a existência do trabalho da mulher, na realização de atividades domésticas, desde a Idade Média, foi a Revolução Industrial o marco histórico da entrada das mulheres no mercado de trabalho.

Com a Revolução Industrial, marco da consolidação do capitalismo, a mulher passa a ser incorporada nas relações produtivas sob condições desumanas, tendo em vista a intensificação do trabalho, a extensa jornada de trabalho e o rebaixamento salarial, para atender aos imperativos do acelerado processo de acumulação. Mesmo com essa realidade, as mulheres dos grupos menos privilegiados necessitavam do trabalho como forma de subsistência e por isso acabavam se sujeitando aos respectivos ordenamentos. (GUIRALDELLI, 2007, p.02)

O mesmo autor pontua que nessa conjuntura apresentada, a mulher não saía de casa para o trabalho industrial objetivando sua independência, mas sim para se tornar um ser submetido aos imperativos do capitalismo emergente (GUIRALDELLI, 2007).

No caso brasileiro, Fernandes (1987) situa historicamente o surgimento do capitalismo no Brasil e as transformações sociais capitalistas e observa que ao absorver o capitalismo como sistema de relações de produção e de troca, a sociedade desenvolve uma ordem social típica que organiza institucionalmente o padrão de equilíbrio dinâmico e o adapta às potencialidades econômicas e socioculturais existentes. 
O Brasil corresponde normalmente a essa regra. Nele, as estruturas econômicas, sociais e políticas da sociedade colonial não só moldaram a sociedade nacional subsequente: determinaram, a curto e a largo prazos, as proporções e o alcance dos dinamismos econômicos absorvidos do mercado mundial. Elas se revelaram bastante plásticas em face do que se poderia chamar de reorganização do mercado colonial, adaptando-se rapidamente à dupla polarização dos negócios de exportação e de importação, controlados economicamente por um centro hegemônico externo, mas dirigidos politicamente a partir de dentro. (FERNANDES, 1987, p. 150))

Assim sendo, com a consolidação do sistema capitalista, ocorreram várias mudanças na dinâmica das relações sociais, incluindo o trabalho, favorecendo, portanto, a inserção das mulheres no mercado de trabalho. No Brasil, Segundo Guiraldelli (2007) as principais mudanças advindas com a reestruturação produtiva datam da década de 1980, todavia, a participação da mulher no mercado de trabalho se remete ao ano de 1932 quando as mulheres passaram a constituir um segmento especial da força de trabalho.

Tal episódio pode ser considerado como o grande álibi do sistema produtor de mercadorias, que passa a incorporar em grande escala o trabalho feminino diante do rebaixamento salarial, trazendo grandes êxitos para o triunfo do capitalismo. A partir disso, o novo sistema passa a envolver todos os entes familiares na produção, onde os trabalhadores, independente de sua idade, sexo, raça/etnia ou nacionalidade estariam submetidos ao domínio direto do capital. (GUIRALDELLI, 2007, p. o3)

Para melhor compreensão desta questão, insta por em relevo as perspectivas de compreensão de gênero, considerando que este não se confunde com sexo. O lugar subordinado das mulheres nas relações sociais é observado sem dificuldades, a posição de dona da casa submissa às demandas do marido e dos filhos é historicamente determinante. Segundo Barbieri (1993, p. 04), gênero é o reconhecimento "[...] de uma dimensão da desigualdade social até então não trabalhada, subsumida na dimensão econômica, seja nas teorias das classes ou nas teorias da estratificação social".

Neste diapasão Maia (2011) assevera,

Uma longa elaboração teórica feminista construiu o gênero como uma categoria analítica utilizada para problematizar a produção das diferenças sexuais, de papéis sociais ancorados em determinismos biológicos e para denunciar a divisão binária, naturalizada e hierarquizada do mundo. (2011, p. 36)

Ainda nesta mesma toada, e para auxiliar na compreensão das questões que envolvem o trabalho, importante frisar lição de Bourdieu (2014),

O mundo social constrói o corpo como realidade sexuada e como depositário de princípios de visão e de divisão sexualizantes. Esse programa social de percepção incorporada aplica-se a todas as coisas do mundo e, antes de tudo, ao próprio corpo, em sua realidade biológica: é ele que constrói a diferença entre os sexos biológicos, conformando-a aos princípios de uma visão mítica do mundo, enraizadas na relação arbitrária de dominação dos homens sobre as mulheres, ela mesma inscrita, como a divisão do trabalho, na realidade da ordem social. 
A diferença biológica entre os sexos, isto é, entre o corpo masculino e o corpo feminino, e, especificamente, a diferença anatômica entre os órgãos sexuais, pode assim ser vista como justificativa natural da diferença socialmente construída entre os gêneros e, principalmente, da divisão social do trabalho. (2014, p. 24)

Com relação ao conceito de gênero aqui utilizado, a autora Dias salienta,

Necessário olhar a mulher em relação ao Direito, a partir do conceito de gênero; não como sexo biológico, mas em face das diversidades biológicas que se expressam em determinadas relações sociais. As diferenças entre homens e mulheres; decorrentes de toda uma conjuntura social e cultural, acabaram por colocá-los em dois mundos, a ponto de serem tidos como sexos opostos, e não compostos, complementares. Essa divergência posicional, que levou à diferenciação de papéis assumidos, estruturou diferentemente cada um de seus protagonistas. (DIAS, 2004, p. 31)

Expostas as questões que se fazem necessárias para compreensão do conceito de gênero, e da flagrante desigualdade historicamente construída, passaremos adiante a análise das questões centrais do presente artigo. Através das técnicas de pesquisa bibliográfica e documental sobre o tema abordado, buscou-se apresentar dados e discutir temáticas que confirmam a longa e árdua caminhada para a inserção da mulher no mercado de trabalho e a realidade da desigualdade de gênero na atualidade brasileira.

\section{A inserção da mulher no mercado de trabalho: análise do caso brasileiro}

Desde os primórdios as mulheres vêm enfrentando lutas e quebrando paradigmas objetivando garantir seu lugar no mercado de trabalho. As discriminações historicamente e culturalmente construídas, permanecem arraigadas no seio da sociedade tornando o processo de inserção da mulher no mercado de trabalho um verdadeiro enfrentamento de preconceitos, discriminações e constantes desafios. Segundo Dias,

A presença paritária de homens e mulheres nos bancos acadêmicos, no mercado de trabalho, na direção dos veículos, enfim, na sociedade talvez não permita ver que a discriminação contra a mulher ainda existe. Prova disso é a presença rarefeita de mulheres nos órgãos de cúpula do poder, sua ausência no STF e sua escassa participação no cenário político. (DIAS, 2004, p. 45)

A busca pelo protagonismo e empoderamento da mulher, considerando que esta precisa lidar com as tarefas domésticas e com os cuidados com a família é de longa data, uma vez que secularmente o trabalho feminino estava totalmente voltado ao mundo doméstico, interno e do lar.

Os relacionamentos afetivos ainda são vinculados por uma marcante hierarquização, ocupando, homens e mulheres, dois mundos bem polarizados. Enquanto o homem desempenha o papel de provedor e arvora-se como chefe de família, sente-se descompromissado com as atividades domésticas. Resta a mulher relegada à função de reprodutora, responsável pela casa, pela criação dos filhos e pelo cuidado com idosos e doentes. Reservado ao homem o espaço público, fica a mulher confinada ao recinto do lar. (DIAS, 2004, p. 49) 
A tradição cultural brasileira que define o homem como o provedor da família e o responsável por trabalhar fora e ganhar o seu sustento, em oposição à mulher, com o papel de responsável pelos filhos e pela execução dos serviços domésticos, foi um dos fatores que contribuíram para que poucas mulheres fossem a procura de trabalho.

Noutro giro, com o crescente processo de industrialização e expansão do capitalismo, a demanda por mão-de-obra, e pela subsistência das famílias trabalhadoras, demandou a mudança de cenário, ou seja, a mulher, em um determinado momento histórico, precisou deixar sua função - exclusiva - de rainha do lar, para exercer outras funções concomitantes a estas, nascendo, portanto a dupla, tripla ou múltipla jornada de trabalho da mulher. Em termos mais simples, em razão da industrialização e urbanização, a visão econômica e cultural, com relação à inserção e posição da mulher no mercado de trabalho se alterou, todos estes fatores contribuíram para um ambiente propício à entrada de novos trabalhadores no mercado de trabalho, incluindo as mulheres.

O ingresso da mulher no mercado de trabalho ocorreu com a Revolução Industrial, que buscou na mão-de-obra feminina a forma de baratear custos. A baixa auto-estima a fez aceitar remuneração inferior, ainda quando no desempenho da mesma função. Se tal fato levou a mulher para fora do lar, começando a contribuir para o sustento da família, os encargos domésticos continuaram sob sua exclusiva responsabilidade. (DIAS, 2004, p. 49)

As modificações estruturais causadas pela globalização são sentidas em todo o mundo e exigem dos países e das pessoas, uma certa adaptação à esse novo movimento, ou seja, através desta reestruturação produtiva, da competição entre as nações e da nova forma de produção do capital é que a globalização toma forma. Segundo Antunes (2002) o capital ocasionou várias mudanças no processo produtivo, por meio da constituição da forma de acumulação flexível, das formas de gestão organizacional, do avanço tecnológico e dos modelos alternativos taylorismo/fordismo. Esta transição está marcada pela luta das mulheres em prol de reconhecimento no mercado de trabalho.

No Brasil as transformações sociais, políticas e econômicas que repercutiram no modelo patriarcal de família se tornaram mais intensas e aparentes na década de 80. Segundo Nogueira (2004) nos anos 80 e 90, a mundialização do capital emitiu efeitos complexos e contraditórios, afetando desigualmente o emprego, na questão de gênero, ou seja, enquanto que com relação aos homens houve uma estagnação, com relação às mulheres houve um aumento no número de trabalho remunerado em áreas em que predominam os empregos precários e vulneráveis. Neste sentido o autor Mészáros (2004) argumenta que a entrada em massa das mulheres na força de trabalho durante o século XX, apesar de significativa, não resultou em sua emancipação, tendo em vista o surgimento de uma tendência de generalização dos baixos salários, aos quais as mulheres sempre tiveram que se submeter.

Aliada a expansão e abertura do mercado de trabalho e das necessidades do capital, fatores como o desejo de realização pessoal, a necessidade de incrementar a renda familiar ou a obrigação de assumir a responsabilidade total da família contribuíram para que, ao longo das últimas décadas do século XX aumentasse a taxa de participação feminina no mercado de trabalho.

Os dados da pesquisa da Fundação Carlos Chagas ${ }^{1}$ apontam a inserção da mulher no mercado de trabalho no decorrer do tempo no Brasil, e demonstram que enquanto as taxas de atividade masculina mantiveram-se em patamares semelhantes, entre $73 \%$ (setenta e três por cento) e 
$76 \%$ (setenta e seis por cento) em praticamente todo o período, as das mulheres se ampliaram significativamente. No ano de 1976, 29\% (vinte e nove por cento) das mulheres trabalhavam no novo milênio, mais de $40 \%$ (quarenta por cento) mulheres estavam trabalhando ou procurando emprego e mais da metade delas (53\% [cinquenta e três por cento]) em atividade no ano 2007. A pesquisa apresenta, ainda, que a importância crescente das mulheres na força de trabalho pode, também, ser observada de outro ângulo, através da sua participação na população economicamente ativa (PEA), ou seja, em 1976, o contingente feminino na PEA era de $29 \%$ (vinte e nove por cento), e no ano de 2007 ela atinge mais de $40 \%$ (quarenta por cento).

De acordo com os dados mais recentes, obtidos no Relatório Anual Socioeconômico Sobre a Mulher (RASEAM) ${ }^{2}$, divulgado em março deste ano, observa-se que já no ano de 2012, a taxa de atividade das mulheres de 16 a 59 anos era crescente, ou seja, de 64,2\% (sessenta e quatro por cento). Porém, ainda um número inferior à taxa de atividade dos homens que era de $86,2 \%$ (oitenta e seis por cento).

Ainda com base no relatório supracitado, a presença de mulheres nos espaços de poder e decisão é um indicador relevante da igualdade de condições e de oportunidades vivenciadas por elas na sociedade brasileira. Nos cargos de Direção e Assessoramento Superiores (DAS) os dados apontam que as mulheres representam aproximadamente $39 \%$ (trinta e nove por cento) dos postos, enquanto os homens alcançavam o patamar de $61,2 \%$ (sessenta e um por cento). Nesse tocante, embora as mulheres tenham uma relativa vantagem, no que se refere ao nível de escolaridade, em relação aos homens, há ainda uma flagrante desigualdade de gênero na ocupação dos espaços de poder e decisão, ou seja, o acesso aos mais altos níveis de gestão dos órgãos governamentais permaneceu um desafio às mulheres, onde elas apresentaram os menores percentuais de ocupação.

Neste sentido Guiraldelli (2007) pontua que o trabalho feminino ainda é considerado suplementar e destinado à sobrevivência e atendimento das necessidades vitais da família e que, no decorrer dos anos, nota que ainda persistem as profissões consideradas femininas e outras masculinas, conforme atributos físicos e naturais.

É possível afirmar, portanto, que a inserção da mulher no mercado de trabalho foi impulsionada, principalmente, pela expansão do capitalismo e das necessidades do capital. $\mathrm{O}$ que se observa, ainda, é que essa inserção foi marcada por preconceitos e dificuldades, ou seja, inúmeras foram as barreiras a serem transpostas por elas e os desafios ainda permanecem, conforme se verá adiante, considerando as condições de precariedade do trabalho feminino e as diferenças salarias, para os mesmos cargos, entre homens e mulheres.

\section{Divisão (Sexual) do Trabalho}

O termo divisão do trabalho é encontrado em estudos oriundos de diversas áreas do conhecimento. Em termos genéricos refere-se às diferentes formas que os seres humanos, ao viverem em sociedades históricas, produzem e reproduzem a vida. Em sua obra Karl Marx aponta a divisão social do trabalho como uma consequência perversa do sistema capitalista, ao retirar do trabalhador o domínio da produção e transferir para a mão do capitalista, ou seja, causa a alienação do trabalhador do processo de produção. Ainda segundo Marx, sobre a Divisão do Trabalho, os vários estágios desta correspondem às formas de propriedade da matéria, dos instrumentos e dos produtos do trabalho verificados em cada sociedade, nos diversos momentos históricos. 
Neste sentido, com a complexidade da vida em sociedade e o aprofundamento da integração entre diferentes grupos e sociedades, várias ramificações desta divisão do trabalho podem ser observadas.

Com relação a divisão sexual do trabalho, objeto do presente estudo, Hirata (2007) explica:

A divisão sexual do trabalho é a forma de divisão do trabalho social decorrente das relações sociais entre os sexos; mais do que isso, é um fator prioritário para a sobrevivência da relação social entre os sexos. Essa forma é modulada histórica e socialmente. Tem como características a designação prioritária dos homens à esfera produtiva e das mulheres à esfera reprodutiva e, simultaneamente, a apropriação pelos homens das funções com maior valor social adicionado (políticos, religiosos, militares etc.). (HIRATA, 2007, p. 599)

Neste sentido, é possível observar que a segmentação entre os homens e as mulheres é parte integrante da divisão social do trabalho e, pode ser atribuído o surgimento da divisão sexual do trabalho e a forma como ela se estrutura, ao modo de produção capitalista. Desde o surgimento do capitalismo até o período atual, as modalidades de divisão do trabalho entre os sexos, tanto no trabalho assalariado quanto no trabalho doméstico, evoluem no tempo de acordo com as relações de produção (HIRATA, 2002).

Neste mesmo sentido explica outra autora,

A divisão sexual do trabalho é também uma construção social e histórica. Se é certo que o capitalismo utiliza uma estratégia de "dividir para reinar", a configuração dessas divisões é construída socialmente através das relações de classe, de raça, de gênero e das práticas sociais. O capitalismo na América Latina não criou a subordinação das mulheres, mas certamente as relações de produção e reprodução social são aqui também sexuadas e assimétricas, marcadas por uma hierarquia que subordina as mulheres e seus trabalhos (SOUZA-LOBO, 1991, p.170)

É possível observar que a inserção da mulher na cadeia produtiva ocorre ao mesmo tempo em que o mundo do trabalho vem atravessando um estágio de precarização nas formas de produzir.

As vicissitudes no mundo do trabalho na América Latina e no Brasil apresentam algumas consoantes específicas em detrimento do que se verifica nos países da Europa e Estados Unidos. Isso se deve ao fato de serem países que se encontram na posição de subdesenvolvimento e se observa que, mesmo com a inserção da mulher no mercado de trabalho, nesses países ainda se predomina a mão-de-obra masculina e a disparidade salarial entre homens e mulheres. $E$ importante identificar que a desigualdade salarial não é um fenômeno recorrente apenas num contexto local ou nacional e, sim, presente em todo o mundo. (GUIRALDELLI, 2007, p.07)

Noutro giro, insta salientar o posicionamento de Dias (2004) que aponta sobre uma noção equivocada de "natural divisão do trabalho", desta feita, no âmbito familiar, do lar, ao afirmar que cabe apenas à mulher o papel, além de esposa e mãe, de responsabilidade pelas tarefas domésticas. 
Segundo a autora,

[...] essas lides caseiras não são reconhecidas, não gozam de qualquer prestígio social. Por não ser trabalho remunerado, não é contabilizado, não possui valor econômico. Assim, as donas-de-casa são trabalhadoras que não recebem salário, não fazem jus a descanso semanal, limite de jornada, feriados, licenças e nem à aposentadoria ou à previdência social. A obrigação pelo exercício dessas atividades está ligada à equivocada noção de que elas decorrem da natural divisão do trabalho [...] No entanto, a reserva de papéis diferenciados ao homem e à mulher é uma construção cultural, que acaba gerando uma hierarquização pela mais-valia que se atribui às atividades masculinas pela só razão de que os homens ocupam o espaço público, monopolizam o poder econômico e o político. (DIAS, 2004, p. 15)

Atualmente no Brasil o que se verifica é a continuidade da divisão sexual do trabalho, da equivocada "divisão natural do trabalho" no âmbito do lar, e, a permanência de suas consequências.

A pesquisa da Fundação Carlos Chagas ${ }^{3}$ aponta que no período compreendido entre 1970 e 2007, os padrões de localização dos trabalhadores e das trabalhadoras no mercado de trabalho brasileiro apresentaram algumas alterações. No caso das mulheres os serviços (incluindo alojamento e alimentação, educação, saúde e serviços pessoais, serviços domésticos e outros serviços coletivos, sociais e pessoais) mantêm-se como áreas privilegiadas de inserção das mulheres no mercado de trabalho, mesmo que, no decorrer do longo período aqui considerado, venha se dando uma diminuição da ocupação feminina, que, concomitantemente, se diversificou. Assim, em 1970, $54,9 \%$ (cinquenta e quatro por cento) das mulheres ocupadas eram nos serviços e no setor social, em 1998, 47,5\% (quarenta e sete por cento), em 2002, 44,1\% (quarenta e um por cento) e, em 2007, $43,6 \%$ (quarenta e três por cento).

Com relação à desigualdade de gênero, os dados divulgados no Relatório Anual Socioeconômico Sobre a Mulher (RASEAM) em março deste ano apresentam a realidade brasileira no que tange à divisão sexual do trabalho e ao uso do tempo, ou seja, a jornada total das mulheres, somando-se o tempo dedicado ao trabalho principal (mais de 35 horas semanais) e aos afazeres domésticos (quase 21 horas semanais), era sempre superior à jornada total dos homens (quase 42 horas dedicadas ao trabalho principal e 10 horas aos afazeres domésticos). Nestes termos, os afazeres domésticos, os cuidados com a casa e com a família permanecem sob a responsabilidade das mulheres, que, a despeito de trabalharem fora de casa - assim como os homens - continuam exercendo o papel de "dona de casa".

No mesmo relatório supracitado é possível observar que as mulheres encontravam-se igualmente em número reduzido no que tange à ocupação de cargos diretivos em diferentes ramos de atividade econômica, todavia, elas tinham representatividade significativa à frente dos cargos diretivos nas áreas de educação, saúde e serviços sociais (65,6\%) e em aproximadamente $44 \%$ (quarenta e quatro por cento) no setor de alojamento e alimentação. As atividades diretivas nos setores agrícola e de construção apresentaram os menores índices de presença feminina nos altos cargos. Essa configuração está diretamente relacionada às formações cursadas pelas mulheres no ensino técnico e profissional ou no ensino superior.

Além da diferenciação nos postos e cargos de trabalho e das opções por segmentos educa- 
cionais serem diversas, existem ainda as desigualdades salariais. De acordo com Antunes (2002) a expansão do trabalho feminino mostra-se inversamente proporcional quando se trata da temática salarial. $\mathrm{O}$ autor argumenta que a desigualdade de salário oferecido às mulheres contradiz com a sua crescente participação no mercado de trabalho, ou seja, seu potencial de remuneração é bem menor do que aquele auferido pelo trabalho masculino e seus direitos e condições de trabalho são diferentes daqueles concedidos aos homens.

Os homens e as mulheres são separados por setor de atividade (indústria, serviços, etc.), pela qualificação e pelo tipo de trabalho efetuado. Mesmo se as mulheres e os homens exercem a mesma atividade, como trabalhadores não-qualificados na indústria, muito raramente têm o mesmo tipo de tarefas e não são facilmente intercambiáveis (HIRATA, 2002, p.176).

É ainda necessário ressaltar o grande número de mulheres que estão no emprego doméstico, que ainda é essencialmente feminino no Brasil e abriga uma das maiores categorias de trabalhadores. Segundo pesquisa intitulada "O emprego doméstico no Brasil" ${ }^{4}$ divulgada em agosto de 2013 pelo Departamento Intersindical de Estatística e Estudos Econômicos (DIEESE), no ano de 2011 estimava-se que 6,6 milhões de pessoas estavam ocupadas nos serviços domésticos no país sendo que deste total, o contingente de mulheres correspondia a 6,1 milhões (92,6\%). Segundo a mesma pesquisa a remuneração média recebida pelas mulheres nas ocupações domésticas era inferior ao salário mínimo vigente para o período, dado este que revela o elevado grau de desigualdade existente no mercado de trabalho segundo os sexos, para este grupamento específico de atividade, que é majoritariamente composto por mulheres (DIEESE, 2013).

Tendo por base, portanto, todos os dados das pesquisas acima analisadas, verifica-se a existência (e permanência) da divisão sexual do trabalho concomitantemente com a desigualdade de gênero no mercado de trabalho brasileiro, além de observar que existem algumas áreas do setor produtivo em que ainda prevalece a mão-de-obra masculina.

\section{Considerações finais}

Por todo o exposto, o que se verifica no Brasil é que, ao longo das últimas décadas, as mulheres vem buscando a consolidação da sua participação no mercado de trabalho, o que aos poucos vem deixando de ser concebida como secundária ou intermitente. Vários fatores contribuíram para essa mudança de paradigma, ressaltando dentre eles a expansão e consolidação do capitalismo no Brasil que demandou a necessidade da mão-de-obra feminina em vários setores da economia.

A inserção das mulheres nesta realidade é, no entanto, marcada pela desigualdade de gênero e pela divisão sexual do trabalho, ou seja, elas ocupam espaços diferenciados, permanecendo, ainda, como minoria nos postos de direção e maioria nos trabalhos mais precários. Ademais, a trajetória feminina rumo ao mercado de trabalho não significou a sua saída do espaço do lar, o que pode ser percebido pela sua jornada "múltipla" de trabalho e pela concentração de mulheres nos serviços sociais e domésticos.

Com relação especificamente ao serviço doméstico, a presença feminina permanece determinante, sendo possível reconhecer os fatores históricos que contribuem para esta realidade, sendo um deles vinculado à origem da atividade, que é associada ao trabalho escravo - uma vez que até a abolição da escravidão, os afazeres da casa ficavam sob responsabilidade de mulheres negras 
escravizadas e passam pela desvalorização do trabalho reprodutivo (cuidado do lar e da família) realizado pelas mulheres.

Um dos principais pontos a serem ressaltados é a permanência da divisão do trabalho em "feminino e masculino" e a continuidade da disparidade salarial entre homens e mulheres, ou seja, nas relações de gênero as mulheres continuam em desvantagem pois auferem rendimentos menores que os homens mesmo quando ocupam as mesmas funções.

Por outro lado, observa-se que muitas foram as conquistas das mulheres no mercado de trabalho, principalmente nas últimas décadas, o que não evita a permanência de padrões e paradigmas que ainda necessitam ser rompidos.

No Brasil da última década, ocorreram mudanças radicais no estatuto social das mulheres. Maior nível de escolaridade, aumento expressivo da participação na força de trabalho, queda da natalidade e mais acesso à independência econômica e jurídica configuram esse novo quadro. Mais instruídas, as brasileiras vêm aumentando de forma significativa e constante sua participação no mercado de trabalho; nesta década, ocorreu um incremento de $24 \%$ na atividade feminina. O perfil da trabalhadora também mudou, a maioria é casada e tem filhos. A maternidade não afasta mais as mulheres do trabalho, continuam ativas na fase reprodutiva, o que não ocorria anteriormente. Caminho sem volta, as mulheres já são $44 \%$ da população economicamente ativa e $91 \%$ das entrevistadas considera que o trabalho remunerado é fundamental em sua vida. A família, não escapou desta vaga de mudanças, tende a desaparecer o arranjo familiar que atribui prover o sustento da casa exclusivamente ao homem. (ÁVILA, 2014, p. o8)

$\mathrm{Na}$ atualidade, a tendência predominante é que as mulheres busquem permanecer trabalhando e conciliando a vida doméstica com os papéis de esposa e mãe, com a educação dos filhos.

Ressalta-se, por fim, que essa libertação feminina é relativamente nova se for comparada com a histórica dominação masculina, a despeito da existência de legislação no ordenamento jurídico pátrio que garanta a igualdade de direitos e deveres entre homens e mulheres, sem distinção de qualquer natureza.

\footnotetext{
Ainda que o panorama legal não permita tratamento desigualitário em função do sexo, para o fim da discriminação não basta a consagração constitucional da igualdade. O princípio da igualdade formal não é absoluto, é um conceito relativo, impõem-se diferenciações para tornar materialmente iguais entes desiguais. Mister acentuar as diferenças, para que se implementem políticas públicas que dêem um tratamento prioritário às questões de gênero. Por isso, indispensável a adoção de ações afirmativas que busquem o estabelecimento da igualdade material por meio da igualdade de oportunidades. (DIAS, 2004, p. 37)
}

Portanto, o caminho a ser percorrido para se alcançar a plena e efetiva igualdade de gênero no mercado de trabalho e nos espaços de poder ainda é longo e demanda a necessidade de reconhecimento dos desafios a serem enfrentados pelas mulheres, que precisam de intervenções adequa- 
A inserção das mulheres no mercado de trabalho como uma exigência do capital e a divisão sexual do trabalho

das às suas necessidades específicas.

\section{Notas}

1. Disponível em http://www.fcc.org.br/bdmulheres/serie1.php?area=series. Acesso em 13 de julho de 2015.

2. Disponível em http://www.spm.gov.br/central-de-conteudos/publicacoes/publicacoes/2015/livro-raseam_completo.pdf. Acesso em 15 de julho de 2015.

3. Fonte: Disponível em http://www.fcc.org.br/bdmulheres/serie4.php?area=series. Acesso em 13 de julho de 2015.

4. Disponível em: http://www.dieese.org.br/estudosetorial/2013/estPesq68empregoDomestico.pdf. Acesso em 14 de julho de 2015.

\section{Referências bibliográficas}

ANTUNES, Ricardo. Os sentidos do trabalho: Ensaio sobre a afirmação e a negociação do trabalho. 6. ed. São Paulo: Boitempo, 2002.

ÁVILA, Maria Betânia; FERREIRA, Verônica (org). Trabalho remunerado e trabalho doméstico no cotidiano das mulheres. Instituto Patrícia Galvão. Recife: SOS Corpo, 2014.

BARBIERI, Teresita de. Sobre a categoria Gênero: uma introdução teórico-metodológica. Recife: SOS Corpo, 1993.

BOURDIEU, Pierre. A dominação masculina. 1 $^{\text {a }}$ Ed. Rio de Janeiro: BestBolso, 2014.

BRASIL. Presidência da República. Secretaria de Políticas para as Mulheres. Relatório Anual Socioeconômico da Mulher. $1^{\text {a }}$ Impressão. Brasília: Secretaria de Políticas para as Mulheres, março de 2015. 181p. Disponível em http://www.spm.gov.br/central-de-conteudos/publicacoes/ publicacoes/2015/livro-raseam_completo.pdf. Acesso em 15 de julho de 2015.

DIAS, Maria Berenice. Conversando sobre a mulher e seus direitos. Porto Alegre: Livraria do Advogado Editora, 2004.

DIEESE, O emprego doméstico no Brasil. Estudo e Pesquisa nº 68. Agosto de 2013. Disponível em http://www.dieese.org.br/estudosetorial/2013/estPesq68empregoDomestico.pdf. Acesso em 14 de julho de 2015 .

FLORESTAN, Fernandes. A revolução burguesa no Brasil: ensaio de interpretação sociológica. $3^{\mathrm{a}}$ ed. Rio de Janeiro: Guanabara, 1987.

GOMES, Gisele Ambrósio. História, Mulher e Gênero. Disponível em http://www.ufff.br/ virtu/files/2011/09/HIST\%C3\%93RIA-MULHEREG\%C3\%8ANERO.pdf. Acesso em 15 de julho de 2014 . 
GUIRALDELLI, Reginaldo. Presença feminina no Mundo do Trabalho: História e Atualidade. Revista de Estudos do Trabalho. Ano I - Número I - 2007. Disponível em http://www. estudosdotrabalho.org/Guiraldelli_RETo1.pdf. Acesso em 13 de julho de 2015.

HIRATA, Helena; KERGOAT, Daniele. Novas configurações da divisão sexual do trabalho. Cadernos de Pesquisa, v. 37, n. 132, set./dez. 2007.

, Helena. Nova divisão sexual do trabalho?: um olhar voltado para a empresa e a sociedade. São Paulo: Boitempo, 2002.

MAIA, Cláudia de Jesus. A invenção da solteirona: conjugalidade moderna e terror moral: Minas Gerais 1890-1948. Ilha de Santa Catarina. Ed. Mulheres, 2011.

MARX, Karl. O Capital. Livro I. São Paulo: Abril Cultural, 1984. vol. I, tomo 2.

MÉSZÁROS, István. Para Além do Capital. São Paulo: Boitempo, 2004.

NOGUEIRA, Claudia Mazzei. A Feminização no Mundo do Trabalho. São Paulo: Autores Associados, 2004.

POLANY, Karl. A grande transformação: as origens da nossa época. 2. Ed. Rio de Janeiro. Elsevier, 2012.

PROBST, Elisiana Renata. A evolução da mulher no mercado de trabalho. Disponível em http://www.rhportal.com.br/artigos/rh.php?idc_cad=xg7w7vuh9. Acesso em 03 de junho de 2015.

SAFFIOTI, Heleieth I.B. O Poder do Macho. São Paulo: Moderna, 1987.

SCOTT, Joan. Gênero: uma categoria útil de análise histórica. Educação e Realidade, Porto Alegre, v. 20, n. 2, jul./dez., 1995.

SOUZA-LOBO, Elisabeth. A classe operária tem dois sexos: trabalho, dominação e resistência. São Paulo: Brasiliense, 1991. 